\title{
Correction to: The Health and Wellbeing of Older Women Living Alone in the UK: Is Living Alone a Risk Factor for Poorer Health?
}

\section{Cat Forward ${ }^{1} \cdot$ Hafiz T. A. Khan ${ }^{2} \cdot$ Pauline Fox $^{3} \cdot$ Lee Usher $^{1}$}

Published online: 14 September 2021

(c) Springer Science+Business Media, LLC, part of Springer Nature 2021

\section{Correction to: Ageing International https://doi.org/10.1007/s12126-021-09426-w}

The original article has been corrected. The correct author names should read:

Cat Forward

Hafiz T.A. Khan

Pauline Fox

Lee Usher

The affiliations remain the same.

In Table 4, the odds ratio from the logistic regression predicting life satisfaction for those who are widowed should read '1.666' rather than \#\#\#\#\#\#.

Publisher's Note Springer Nature remains neutral with regard to jurisdictional claims in published maps and institutional affiliations.

The original article can be found online at https://doi.org/10.1007/s12126-021-09426-w.

Cat Forward

catherine.forward@kcl.ac.uk

1 The College of Nursing Midwifery and Healthcare, University of West London, London, England

2 Public Health Group, College of Nursing, Midwifery and Healthcare, University of West London, London, England

3 The Graduate Centre, University of West London, London, England 